\title{
KUASA PENDIDIKAN ERA GLOBAL PADA SENI TRADISI GENGGONG DI DESA BATUAN, STUDI KASUS SENI PERTUNJUKAN GENGGONG
}

\author{
Oleh \\ I Nyoman Winyana \\ Dosen Fakultas Pendidikan dan Seni UNHI \\ Nyoman.winyana@yahoo.com \\ I Made Sugiarta \\ sugiartamade@unhi.ac.id \\ Dosen Fakultas Pendidikan, UNHI Denpasar \\ I Putu Gede Padma Sumardiana \\ padmasumardiana@unhi.ac.id \\ Dosen Fakultas Pendidikan, UNHI Denpasar
}

\begin{abstract}
ABSTRAK
Salah satu penyebab keberadaan kesenian Genggong menjadi tidak populer dalam kehidupan masyarakat masa Global adalah peran pendidikan yang diduga tidak berpihak pada seni Genggong seperti di Desa Batuan. Seni pertunjukan Genggong Batuan di era tahun 1973 sempat menjadi karya seni pertunjukan yang mengundang perhatian khususnya pada pertunjukan seni hiburan. Kekhasan dan keunikan bentuk karya ternyata tidak cukup mampu mempertahankan populeritasnya di panggung hiburan.

Kajian tulisan ini berangkat dari metode kualitatif yang dirancang guna memperoleh jawaban secara lebih mendalam. Analisis data dilakukan dengan memperhatikan keabsahan data langsung di lapangan selain dokumentasi tersimpan. Teori yang dipakai membedah persoalan kuasa adalah diambil dari teori kuasa yang menekankan pada ranah kuasa dan juga habitus yang terjadi di masyarakat.

Hasil akhir kajian ini adalah temuan yang berhubungan dengan proses pendidikan seni tradisional Genggong nyatanya tidak terkait dengan aktivitas kegiatan yang hiburan. Keterlantaran yang diakibatnya oleh perubahan gaya hidup dan struktur yang kurang berpihak pada seni Genggong Desa Batuan.
\end{abstract}

Kata Kunci; Kuasa, Pendidikan, Seni Genggong Batuan

\section{ABSTRACT}

One of the causes of the existence of Genggong art became unpopular in the lives of the people of the Global period was the role of education which was allegedly not in favor of Genggong art such as in the Village of Batuan. The performance of Genggong Batuan in the 1973 era had become a performance art work that drew attention especially to entertainment art performances. The peculiarity and uniqueness of the form of work turned out to be not enough to maintain its popularity on the entertainment stage.

The study of this paper departs from qualitative methods designed to obtain answers in more depth. Data analysis is done by paying attention to the validity of 
direct data in the field besides the stored documentation. The theory used to dissect the issue of power is taken from the theory of power which emphasizes the realm of power and also habitus that occurs in society.

The final result of this study is that findings related to the process of traditional Genggong art education are in fact not related to entertainment activities. The negligence that was caused by changes in lifestyle and structure was not in favor of Genggong Desa Batuan art.

Keyword: Power of attorney, education, rock art

\section{Latar Belakang}

Kajian kuasa pendidikan era Global pada seni Genggong di Desa Batuan menarik perhatian karena beberapa persoalan yang muncul pada seni pertunjukan Genggong di Desa Batuan. Pertama keberadaan seni Genggong telah dianggap sebagai dinasti aset Desa Batuan yang pernah populer sebagai seni hiburan. Di samping itu keberadaan seni Genggong Batuan juga pernah menjadi pertunjukan primadona bagi hotel-hotel di Bali. Dalam perjalanannya tampaknya keberadaannya tidak semulus apa yang diharapkan bersama. Seiring dengan kondisi pariwisata Bali yang berubah-ubah sepertinya juga memberi pengaruh terhadap keberlangsungan seni pertunjukan Genggong di Desa Batuan.

Di samping itu peran pendidikan dalam menumbuhkan kesadaran terhadap kesenian lokal (seni Genggong) yang menjadi kebanggaan masyarakat Desa Batuan sepertinya telah menjadi ajang kompetisi dalam mengenali seni tradisi yang ada. Padahal kenyataannya dengan para pelaku seni Genggong di Batuan dan juga keberadaan pendidikan yang mapan di masyarakat sepertinya seni Genggong harusnya mendapatkan perhatian dalam penyelenggaraan pendidikan. Kondisi seni pertunjukan Genggong di Era Global yang semakin terpuruk keberadaannya jelas memiliki kaitan terhadap proses pendidikan yang diselenggarakan pelaku pendidikan.

Perhatian dalam pendidikan penting menjadi kajian dalan tulisan ini mengingat di era global kesadaran yang dikehendaki akan memberikan keselamatan terhadap jenis karya seni tradisi seperti Genggong agar mampu bertahan adalah sebuah perjuangan untuk mengakali arus budaya global. Memperkuat kesadaran masyarakat agar mampu mengembalikan kesadaran untuk menghargai budaya lokal merupakan semangat yang perlu dibangun dan didorong secara berkelanjutan. Memberikan kekuatan pada kesadaran masyarakat di Desa Batuan melalui pendidikan adalah proses regenerasi yang berkaitan dengan aset lokalitas. 
Membentengi perilaku masyarakat Desa

Batuan agar tidak terjerumus dalam budaya global adalah cita-cita bersama agar terpelihara nilai dan budaya tradisi sebagai kekuatan masyarakat.

\section{Kajian Teoritis}

Lokasi dan objek kajian yang dianalisis dalam tulisan ini adalah seni pertunjukan Genggong di Desa Batuan. Saat ini seni Genggong sudah termasuk langka karena hanya ditemui dibeberapa wilayah saja dan itupun sudah tidak aktif. Termasuk Genggong di Desa Batuan walaupun pelaku masih dapat dijumpai namun secara aktivitas pertunjukan sudah jarang dijumpai.

Kondisi giografis yang terletak di Desa Batuan kecamatan Sukawati, kabupaten Gianyar. Mayoritas sebagai pemeluk Hindu dengan adat istiadat budaya yang kental. Walaupun demikian pengaruh global juga terlihat dari fisik tatanan desa yang mengacu ke arah pemanfaatan teknologi yang semakin tak terbendung. Analisis tulisan ini menggunakan metode kualititif, sehingga kesimpulan yang diharapkan dapat dijelaskan secara lebih mendalam.

Jejak tulisan yang mendasari kajian ini diambil dari beberapa tulisan yang membahas tentang seni Genggong seperti;
Bandem (2013) dalam tulisan "Sejarah gamelan di atas Panggung”. Rai S.(2000) yang mencatatkan hasil penelitian tentang laras Genggong yang mendekati laras salendro, termasuk Budiarta (2014) yang lebih fokus pada tari Genggong. Demikian juga dengan Jaap Kunst, menjelaskan dalam bukunya yang berjudul "Hindu Javanese Musical Instruments" (1968). Yudabhakti, dalam jurnal Kajian Bali, Refleksi Seni Bahasa Bali, Universitas Udayana Denpasar, Vol 06, No. 1, April 2016, dengan judul "Marginalisasi dan Revitalisasi Wayang Kulit Parwa di Kabupaten Gianyar”. Jaap Kunst dengan judul bukunya "De toonkunst van Bali" (1924), yang memberi data awal termasuk pengetahuan awal tentang seni Genggong di Desa Batuan. Penulis berkeyakinan bahwa tema tulisan yang ada sama sekali tidak disinggung di dalam tulisan sebelumnya.

Konsep yang patut mendapat perhatian dalam kajian ini adalah kuasa pendidikan era global, seni pertunjukan Genggong dan Desa Batuan. (a) Kuasa pendidikan era global; ada banyak paham tentang kuasa namun berkaitan dengan teori Boerdieu tentang pemainan kuasa dimaknai sebagai habitus dari perilaku terstruktur yang sudah dianggap sebagai 
perilaku yang terbiasa dan pada akhirnya dimaknai sebagai struktur yang menguasai perilaku manusia. Dalam praktiknya di masyarakat kebiasaan itu sudah dianggap sebagai bentuk kewajaran bukan lagi dalam pemahaman penindasan Setiawan (2014)

(https.wwwslideshare.netsyuhadak).

Dalam pandangan Marx dan Engels melihat kuasa sebagai yang materi dan intelektual sebagai bentuk kuasa, selain juga relasi materi termasuk distribusi hasil produksi yang mampu menguasai budaya masyarakat. Dalam kontek hegemoni kuasa dimakani sebagai budaya dominan culture; yakni kuasa yang terjadi karena material, residual; kuasa yang terjadi karena tradisi yang berkelanjutan, dan budaya emergen merupakan budaya baru yang mampu menguasai perilaku kehidupan Setiawan (2014) (https.wwwslideshare.netsyuhadak).

Pendidikan merupakan proses yang dilakukan secara sadar untuk memenuhi tujuan penting dalam kehidupan manusia yakni mengubah pengetahuan, kemampuan (skill), dan juga perilaku menjadi lebih beradab. Dalam praktiknya muncul kemudian istilah pendidikan formal, nonformal, dan informal.
Era global merupakan suatu masa di mana batas dan keadaan secara universal mulai menipis akibat pengaruh teknologi, informasi, gaya hidup, pariwisata, ekonomi, yang mengakibatkan kecendrungan terjerumus pada budaya massal yang tidak memiliki identitas yang jelas, dan berorientasi pada budaya hedoisme.

Seni pertunjukan Genggong merupakan salah satu bentuk kesenian yakni seni pertunjukan musik, tari, dan dramatari yang berfokus pada instrumen Genggong. Suatu alat musik yang terbuat dari bahan pugpug atau batang daun pohon Jaka. Dibuat sedemikian rupa sehingga mampu dimainkan secara musikal. Instrumen inilah yang menjadi pengkhususan dan ciri keunikan yang dimilikinya. Selain bentuk yang tampaknya memiliki perbedaan khusus terhadap seni tradisi lainnya di Bali. Namun sangat disayangkan pada akhirnya malah keberadaannya kurang mendapat perhatian pihak-pihak pelaku.

Ada perubahan yang mengakibatkan munculnya kontestasi sebagai dampak idiologi dalam mengkonsumsi hiburan mulai mengalami kebosanan terhadap seni tradisional Genggong di Desa Batuan. Muncul berbagai persoalan sepertinya 
masyarakat telah dipengaruhi oleh dunia global yang mengacu pada hiburan yang bersifat praktis, menghibur, tidak menyukai pola terstruktur, dan juga tidak mau menikmati seni hiburan yang bersifat berat dan sarat dengan filosofis yang menggurui.

\section{Pembahasan}

Penyelenggaraan

pendidikan

merupakan satu-satunya cara yang dikembangkan di dalam kehidupan masyarakat desa dalam kerangka untuk mencapai peradaban masyarakat yang lebih maju. Tradisi pendidikan yang berkembang di Indonesia termasuk di Desa Batuan mempercayakan sistem pendidikan lewat pendidikan formal sekolahan, dan secara informal dilakukan lewat kursus-kursus selain juga pendidikan nonformal yang ditemui dilingkungan sosial seperti keluarga dan juga komunitas sosial.

Pendidikan yang dikembangkan tidak saja untuk mengembangkan pengetahuan secara umum namun juga menyasar keahlian yang dibutuhkan guna menghadapi kehidupan, termasuk tata perilaku yang dianggap penting untuk menjadikan seseorang lebih humanis dan toleran.
Melihat perkembangan pendidikan dalam kaitan seni tradisi di Desa Batuan Sukawati, Gianyar dapat diurai bahwa penyelenggaraan pendidikan sudah berlangsung secara mentradisi sebagai habitus. Setiap anak memperoleh kesempatan untuk turut terlibat di dalam pendidikan. Dalam kaitannya dengan pendidikan seni budaya kenyataannya menunjukan bahwa materi yang dipelajari mengikuti arahan petunjuk kurikulum yang memberi data secara konsep pengetahuan umum tentang seni nusantara mendominasi hampir $70 \%$ sedangkan $30 \%$ lainnya mempelajari seni tradisional nusantara.

Dalam pedidikan formal, untuk pembelajaran seni tradisional lokal sebagai pilihan materi hanya bersifat pengenalan dasar. Belum mampu masuk pada praktik langsung untuk memainkan alat. Keterbatasan waktu dan juga serana menjadi kendala. Kondisi lain tercipta dari pendidikan nonformal yang justru lebih kosentrasi untuk masuk pada posisi praktik dalam pengenalan seni tradisional baik pada seni tari, musik. Termasuk pendidikan informal yang dikembangkan oleh sanggar-sanggar justru lebih menekankan pada praktik tari dan musik tradisi yang lebih populer. Materi seni 
Genggong tidak tergolong dalam penjaga tradisi kuno belum menyikapi instrumen yang populer.

seni langka dalam proses pendidikannya.

Ketidakpopuleran itu menjadikan Padahal dengan membangun unit kegiatan posisi seni Genggong bukan menjadi seni langka (seni Genggong) akan menjadi suatu pilihan materi di dalam proses potensial dikembangkan ke arah pembelajaran seni tradisi. Bagi pendidikan bilamana ada program masyarakat yang terlibat di dalam kebijakan yang mampu melakukan pendidikan dapat dikatakan telah menjadi aktivitas kegiatan seni Genggong.

pelaku yang melupakan seni Genggong sebagai materi dasar pengenalan kesenian lokal menjadi benar adanya sebagian masyarakat di Batuan sudah dianggap berjalan sangat wajar.

Organisasi sosial masyarakat Batuan seperti "banjar" juga tidak terlibat dalam menjaga seni Genggong di Batuan. Hal itu terjadi karena pelaku-pelaku yang ada mulai kehilangan kepercayaan untuk

Kuasa yang dimainkan pelaku menjadikan Genggong sebagai pusat dalam bidang pendidikan ternyata telah menjauhkan generasi sebagai pelatihan seni. Ketidakpercayaan yang penyambung kehidupan seni Genggong, muncul diantara pelaku seni Genggong, malah menyeret keberadaan seni bahkan menjadi terputus sama sekali. Hal Genggong terpuruk. Perlu adanya itu juga didukung oleh tradisi masyarakat pembenahan dan cara perlakuan yang Desa Batuan yang tidak melibatkan aktivitas kegiatan budaya dengan melibatkan seni Genggong. Secara dominasi pelaku pendidikan di Desa Batuan secara tidak sadar sudah tepat agar Genggong dapat dilirik sebagai karya yang berpotensi bagi kemajuan Desa Batuan sendiri. menghegemoni keberadaan seni Genggong.

Aktivitas seni Genggong dimungkinkan jika seluruh komponen yang peduli mampu menyadari bahwa pengaruh budaya global sedikit demi

Padahal secara aktivitas sosial tidak sedikit akan menggerogoti karya seni menutup kemungkinan terjadi proses lokal dan mengubah seni lokal menjadi pendidikan lewat penyertaan seni sama sekali tidak berguna, kehilangan Genggong pada setiap kegiatan sosial, daya sehingga tidak lagi menjadi pusat termasuk pemerintahpun sebagai garda kegiatan yang dapat memberi identitas 
yang kuat bagi masyarakat Desa Batuan sendiri. Membangun kesadaran yang utuh lewat praktek budaya yang melibatkan seni Genggong menjadi penting melalui kemasan yang lebih memenuhi standar estetika postmo tanpa mencabut akar budaya yang ada.

\section{PENUTUP}

Dengan demikian dapat dikatakan bahwa seni Genggong menjadi lebih langka dan tidak mudah diamati di era global karena pelaku yang menguasai pendidikan tidak berpihak pada seni Genggong sebagai aset penting masyarakat yang ada di Desa Batuan. Pendidikan formal yang mengacu pada struktur regulasi pusat telah turut memberi peluang terjadinya dominasi dan hegemoni karena tidak melihat seni Genggong sebagai materi pengkhususan.

Ke depannya patut dicermati baik oleh pelaku seni yang langsung terlibat di dalam seni Genggong, masyarakat sebagai pemilik, dan juga pemerintah agar lebih memberi peluang dan melihat kenyataan secara global bahwa identitas seni lokal (seni Genggong) merupakan aset yang mampu dikembangkan untuk menjawab kebutuhan budaya global sehingga menjadi lebih dikenal secara luas oleh masyarakat dunia dan dalam penyelenggaraannya, lembaga pendidikan dalam mengenalkan seni Genggong sebagai aset desa perlu disinergikan.

\section{DAFTAR RUJUKAN}

Adorno, T.W dan Horkheirmer, 2003. "Teori Sosial Kritis, Penerapan dan Implikasinya", (terjemahan Nurhadi). Yogjakarta: Penerbit Kreasi Wacana.

Astita Komang, dkk., 2015. "Peta Kesenian dan Budaya Bali, Seni Pertunjukan Modal Dasar Pesta Kesenian Bali dan Pembangunan Bali Berkelanjutan". Denpasar : Deva Communications.

Bandem I Made, 2013. "Gamelan Bali Di Atas Panggung Sejarah". Denpasar: BP STIKOM Bali.

Bandem I Made, dkk., 2004. "Kaja dan Kelod, Tarian Bali dalam Transisi”. terjemahan I Made Marlowe Makaradhwaja Bandem, Yogyakarta: Istitut Seni Indonesia Yogyakarta.

Barker Chris, 2014. "Kamus Kajian Budaya". Yogyakarta : Kanisius Anggota IKAPI.

Budiarsa I Wayan, dkk., 2014. “Bentuk Pertunjukkan Dramatari 
Genggong di Desa Batuan

Gianyar". Denpasar: Jurusan Seni

Tari, Fakultas Seni Pertunjuakan

Institut Seni Indonesia Denpasar.

Darsana I Ketut, dkk.,2002. “Dokumentasi

Tari-Tari Tradisonal Bali".

Denpasar: Dinas Kebudayaan

Propinsi Bali.

Djelantik A.A.M.,1992. “ Ilmu Estetika

Jilid I dan II Falsafah Keindahan

dan Kesenian". Denpasar Sekolah

Tinggi Seni Indonesia (STSI).

George Dickie, 1979. Aesthetics.

Idianapolis: Pegasus, Bobbs-

Meril Education Publishing.

Gie The Liang, 1996. Filsafat Seni.

Yogyakarta: Pusat Belajar Ilmu Berguna.

Griya I Wayan, dkk, 1998. Taksu Never anding art creativity. Denpasar:

Cultural Affairs Office of

Province and Taksu Foundation

Ibrahim Idi Subandi, 1997. Lifestyle ecstasy, Kebudayaan POP Dalam

Masyarakat

Komuditas

Indonesia. Yogyakarta: Diterbit oleh Jalasutra

Kunst Jaap and C.J.A. Kunst Van Wely, 1925. The Toonkunst van Bali. Amsterdam: Waltervreden;
Koninklikjk Bataviaasch

Genootschaap,

Kunst Jaap, 1968. Hindu Javanese Musical Instruments $2^{\text {nd }} e d^{\prime \prime}$. Amsterdam: The Hague; Matinus Nijhoff

Kontjaraningrat, 1993. " Masyarakat Terasing”. Jakarta: Gramedia.

Langer, S.K., 1971. Philosopy in New Key. Harvard Universitity: Cambride, Massachusetts

Oka Sudira, 2010, Ilmu Seni dan Praktik.

Jakarta Timur: Inti Prima

Promosindo

Piliang Yasraf Amir, 2010. Semiotika dan Hipersemiotika, Kode, Gaya dan Matinya Makna, Ed IV Plus DVD. Bandung : Matahari

Racki Christian,1998. The Sacred Dances Of Bali . Denpasar: CV. Buratwangi.

Rai, S. I Wayan, 2001. Gong Antologi Pemikiran. Denpasar: Penerbit Mangi Press

Sadguna I Gede, I Made Indra, dkk., 2015. Genggong Dalam Karawitan Bali, Sebuah Kajian Etnomusikologi. Denpasar: Fakultas Seni Pertunjukkan Institut Seni Indonesia. 
Sadguna Indra, Sutirtha, 2015. Genggong

Dalam Karawitan Bali, Sebuah

Kajian Etnologi. Denpasar:

Fakultas Seni Pertunjukan ISI

Denpasar.

Soedarsono, R.M., $1999 . \quad$ Seni

Pertunjukan Indonesia di Era

GLobalisasi. Jakarta: Direktorat

Jendral Pendidikan Tinggi

Departemen Pendidikan dan

Kebudayaan.

Suartaya Kadek, 1985. Genggong Di Desa

Batuan. Denpasar: Penerbit

Akademi Seni tari Indonesia Encyclopedia, Wikiepedia,Org. Bebas

Denpasar.

Suedarsono, Tati Narawati, 2011. KBBI.web.id, Marginalisasi, 2016).

Dramatari Indonesia Kontinuitas

dan Perubahan. Yogyakarta:

Gajah Mada University Press

Sutrisno Mudji, Hendar Purwanto, 2005.

Teori-Teori

Kebudayaan.

Yogyakarta: Kanisius
Sugiyono, 2005. Metode Penelitian Kualitatif, Kuantitatif, dan R \& D. Bandung: Alfa Beta

Tetang Simbol. Denpasar: Dharma

Miles dan, Mattheu B. \& A. Michael Humberma. 1992. Analisis Data Kualitatif. Diterjemahkan Oleh Tjejep Rohendi Rohidi. UI Press: Jakarta.

\section{Unduhan :}

Indonesia, Globalisasi, 2016.

KBBI.co.id./ Genggong, 2016)

Ikwan

Setiawan, 2014 https, wwwsildeshere. netshyuhadak. 